\title{
Relato de um caso de Síndrome de Ramsay Hunt
}

Carla Carriço*

\section{RESUMO}

A otalgia é um sintoma comum em Medicina Geral e Familiar. Este caso serve para alertar para uma etiologia rara de otite. O síndrome de Ramsay Hunt é uma complicação rara da infecção pelo vírus herpes zóster. O quadro clínico é caracterizado por paralisia facial periférica, lesões vesiculares no ouvido externo ou orofaringe. Relata-se o caso de uma mulher que se apresentou na consulta com história de otalgia tipo queimadura, paralisia facial periférica homolateral e lesões vesiculares no pavilhão auricular direito. Foi-lhe atribuído o diagnóstico de síndrome de Ramsay Hunt. Este é a segunda causa de paralisia facial atraumática. O diagnóstico é clínico: dor e lesões vesiculares no dermátomo, por vezes, associada a epífora, obstrução nasal, sialorreia e paralisia facial periférica. As complicações incluem: encefalite, mielite, paralisia de nervos cranianos e de nervos periféricos. O maior estudo retrospectivo disponível mostrou benefício no tratamento precoce com aciclovir e prednisolona. O prognóstico é favorável, $75 \%$ dos doentes recuperam completamente em sete dias.

Palavras-chave: Herpes Zoster do Ouvido Externo; Otite Externa; Otalgia.

\section{INTRODUÇÃO}

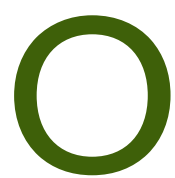

Síndrome de Ramsay Hunt foi descrito pelo autor que lhe deu o nome em 1907. É provocado pelo vírus herpes zóster (VHZ) e é caracterizado por paralisia facial periférica acompanhada de eritema vesicular do ouvido externo ou boca e outros sinais/sintomas como acufenos, diminuição da acuidade auditiva, náuseas, vómitos, vertigem e nistagmo. ${ }^{1}$ A otalgia é um sintoma comum em Medicina Geral e Familiar (MGF), contudo os casos de otites a VHZ são pouco frequentes. Pretende-se com este caso destacar os sinais que alertam para esta patologia.

\section{DESCRIÇÃO DO CASO}

Sexo feminino, 68 anos, raça branca. Apresentou-se com otalgia e dor na hemiface direita intensa tipo queimadura, constante, agravada pela palpação e mastigação e sem factores de alívio, com três dias de evolução. Negava otorreia, otorragia, acufenos, vertigens, febre e queixas respiratórias. Encontrava-se medicada com

*Interna de Medicina Geral e Familiar na USF do Feijó, ACES Almada.
Amoxicilina+ácido clavulânico 875+125mg bid e diclofenac $75 \mathrm{mg}$ bid há $48 \mathrm{~h}$ sem melhoria. Doente hipertensa, tiroidectomizada, com osteoporose e hérnia do hiato, medicada com cálcio+vitamina D3 1500 mg + 400 U.I./dia, lisinopril 20mg+hidroclorotiazida 12,5mg/dia, levotiroxina $0,1 \mathrm{mg} /$ dia e omeprazol 20mg/dia. Negava consumos nocivos. Tinha as vacinas actualizadas. À observação: normotensa, apirética, otoscopia à direita com edema e eritema do canal auditivo externo (CAE), membrana timpânica sem sinais inflamatórios e adenopatia submandibular direita com dois centímetros de diâmetro de características benignas. Assumiu-se o diagnóstico de otite externa. Manteve a antibioterapia e iniciou clonixina $300 \mathrm{mg}$ tid. Regressou $24 \mathrm{~h}$ depois por assimetria facial. Negava alterações da fala, visão e da força/sensibilidade dos membros. Exame objectivo sobreponível ao anterior, mas com lesões vesiculares de novo no CAE e pavilhão auricular direito; hiperémia conjuntival direita e exame neurológico sem alterações, excepto desvio da comissura labial com incapacidade de elevação da mesma e incapacidade de encerramento do olho direito sugestiva de paralisia facial periférica direita (grau V na escala de House-Brackmann). 
Admitiu-se o diagnóstico de Síndrome de Ramsay Hunt (72h após o início das queixas). Iniciou aciclovir $800 \mathrm{mg}$ de qid (completou sete dias), pregabalina 50mg tid (completou 15 dias) e lágrimas artificiais. Melhoria sintomática em $48 \mathrm{~h}$, mantendo a paralisia facial periférica. Fez betametasona $14 \mathrm{mg} / 2 \mathrm{~mL}$ intramuscular toma única e fisioterapia durante quinze dias. Após quatro semanas estava totalmente recuperada (grau I na escala de House-Brackmann).

\section{COMENTÁRIO}

A incidência do Sindrome de Ramsay Hunt é 5/ / 100000 habitantes, sendo a segunda causa de paralisia facial atraumática. ${ }^{7}$ Caracteriza-se por dor grave no dermátomo, com irradiação para o pavilhão auricular

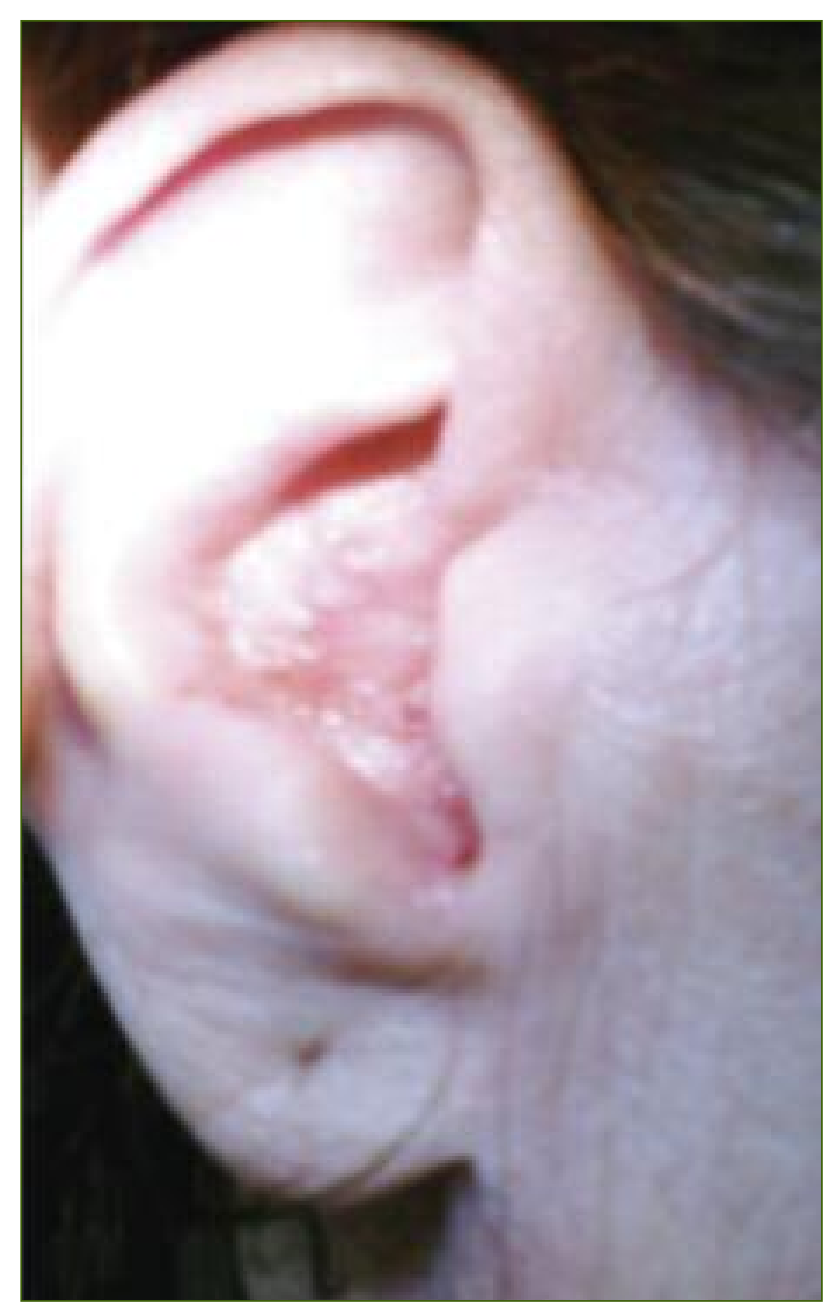

Figura 1. Vesículas no pavilhão auricular. e associada a epífora, obstrução nasal e sialorreia.- ${ }^{1-2,7}$ Faz diagnóstico diferencial com paralisia de Bell, otite externa e nevralgia do trigémio. As complicações incluem: nevralgia pós-herpética, meningite, encefalite, mielite, paralisia de nervos cranianos e paralisia de nervos periféricos. ${ }^{1-4} \mathrm{O}$ diagnóstico é clínico (a análise do liquído cefalo-raquidiano e a ressonância magnética não têm valor diagnóstico nem prognóstico ${ }^{1}$ ). Relatos de caso e estudos retrospectivos sugerem que o tratamento precoce com antiviral e corticoesteróide melhoram o prognóstico. Um esquema terapêutico possível é: aciclovir $800 \mathrm{mg}$ per os cinco vezes/dia durante sete a dez dias e prednisolona $1 \mathrm{mg} / \mathrm{kg} /$ dia per os durante cinco dias. A necessidade de fisioterapia de reabilitação é ainda controversa. ${ }^{5-7}$

Este caso clínico serve principalmente como alerta para a necessidade de o Médico de Família estar constantemente a actualizar conhecimentos de forma a não descurar das causas menos prevalentes de sintomas comuns da prática clínica. Permite ainda destacar a importância da escuta activa, pois na primeira avaliação uma atenção pormenorizada às queixas da doente já indiciava um caso de dor neuropática. Por último, per-

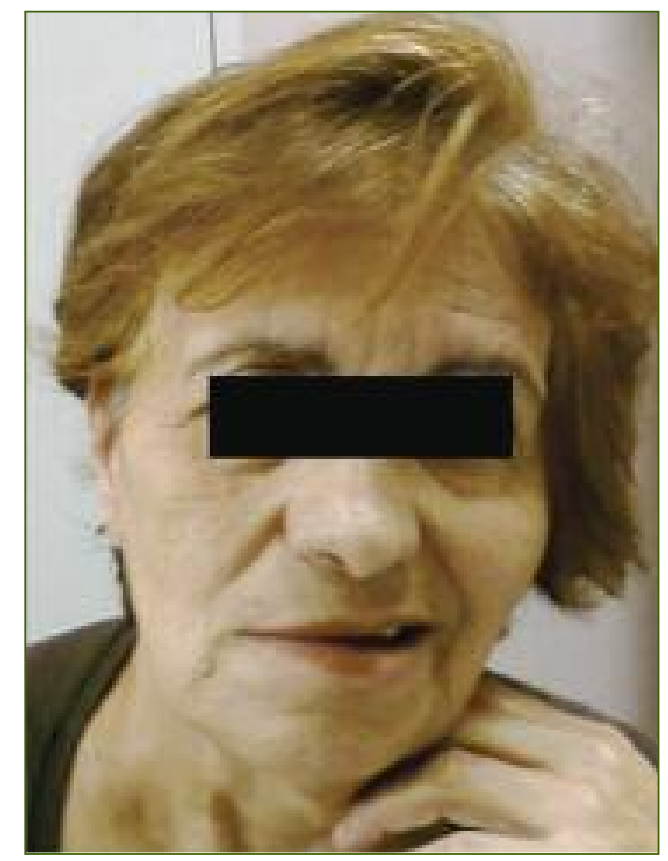

Figura 2. Paralisia facial periférica às $72 \mathrm{~h}$ após o início do quadro clínico. 
mite uma revisão breve desta entidade nosológica - síndrome de Ramsay Hunt - rara nos cuidados de saúde primários.

\section{AGRADECIMENTOS}

Dra. Fátima Santos, Assistente graduada em Medicina Geral e Familiar na Unidade de Saúde Familiar do Feijó.

\section{REFERÊNCIAS BIBLIOGRÁFICAS}

1. Sweeney CJ, Gilden DH. Ramsay Hunt syndrome. J Neurol Neurosurg Psychiatric 2001 Aug; 71 (2): 149-54.

2. Whitley RJ. A 70-year-old woman with shingles: review of herpes zoster. JAMA 2009 Jul 1; 302 (1): 73-80.

3. Izumi AK, Kitagawa K. Ramsay Hunt syndrome: a case report with cranial nerve XII involvement. J Am Acad Dermatol 2007 Dec; 57 (6): 1102-3.

4. Morelli N, Mancuso M, Cafforio G, Gallerini S, Pittiglio L, Tonelli S, et al. Ramsay Hunt syndrome complicated by unilateral multiple cranial nerve palsies. Neurol Sci 2008 Dec; 29 (6): 497-8.

5. Uscategui T, Dorée C, Chamberlain IJ, Burton MJ. Antiviral therapy for
Ramsay Hunt syndrome (herpes zoster oticus with facial palsy) in adults. Cochrane Database Syst Rev 2008 Oct 8, (4): CD006851.

6. Sobn AJ, Tranmer PA. Ramsay Hunt syndrome in a patient with human immunodeficiency virus infection. J Am Board Fam Pract 2001 Sep-Oct; 14 (5): 392-4.

7. Kim D, Bhimani M. Ramsay Hunt syndrome presenting as simple otitis externa. CJEM 2008 May; 10 (3): 247-50.

\section{CONFLITOS DE INTERESSE}

Os autores declaram não possuir conflitos de interesse nem financiamento do estudo.

\author{
ENDEREÇO PARA CORRESPONDÊNCIA \\ Carla Carriço \\ Rua António Gonçalves, $1{ }^{\circ}$ Piso \\ 2810-170 Laranjeiro \\ E-mail: carla.sc@iol.pt
}

Recebido em 26/01/2011

Aceite para publicação em 17/10/2011

\section{ABSTRACT}

\section{A CASE REPORT OF RAMSAY HUNT SYNDROME}

Although earache is a common symptom in General practice, this case report aims to alert the reader to a rare cause of earache. The Ramsay Hunt syndrome is a rare complication of herpes zoster infection. Its clinical features are peripheral facial paralysis and vesicular lesions of the ear or mouth. We report the case of a woman who came to a consultation with her family doctor with a three day history of a burning sensation in her right ear. The following day she had a right-sided facial paralysis and vesicular lesions in the right ear. The diagnosis of Ramsay Hunt syndrome was made. Ramsay Hunt syndrome is the second most common cause of non-traumatic peripheral facial paralysis. The diagnosis is clinical and is made in the presence of pain, vesicular lesions, lacrimation, nasal congestion, salivation and peripheral facial paralysis. The main complications are encephalitis, myelitis and cranial and peripheral nerve palsies. The largest retrospective study published to date showed benefit from early treatment with acyclovir and prednisolone. The prognosis is good and $75 \%$ of all patients have a full recovery in one week.

Keywords: Herpes Zoster Oticus; Otitis Externa; Earache. 